\title{
Comparison of the Results between the First Steroid Treatment Group and the Retreatment Group with Idiopathic Sudden Sensorineural Hearing Loss
}

\author{
Jae Beom Ko ${ }^{\mathbb{D}}$, Chang Hoi Kim, Ki Hun Jo, Hwan Ho Lee, and Jae Hwan Kwon \\ Department of Otolaryngology-Head and Neck Surgery, Kosin University College of Medicine, Kosin University Gospel Hospital, Busan, Korea
}

\section{돌발성 난청에서 스테로이드 초치료군과 재치료군의 성적 비교}

고재범 · 김창회 · 조기헌 · 이환호 · 권재환

고신대학교 의과대학 복음병원 이비인후과학교실

Received June 28, 2018

Revised July 23, 2019

Accepted August 7, 2019

Address for correspondence

Jae Hwan Kwon, MD, PhD

Department of Otolaryngology-

Head and Neck Surgery,

Kosin University

College of Medicine,

Kosin University Gospel Hospital

262 Gamcheon-ro, Seo-gu,

Busan 49267, Korea

Tel $+82-51-990-6247$

Fax $+82-51-245-8539$

E-mail entkwon@hanmail.net
Background and Objectives Sudden sensoryneural hearing loss (SSNHL) is an otological emergency disease of a non-specific cause. If there is no improvement or if the degree of hearing loss is severe, patients are often referred to other medical institution. Many papers have reported regarding the treatment results of SSNHL, however, most of them failed to mention the fact that patients were referred from other clinics after steroid treatment. This paper would like to compare the treatment results between patient groups who had been referred following steroid treatment and those who received steroid treatment for the first time.

Subjects and Method We retrospectively analyzed 127 patients from January 2015 to August 2017. Patients who received steroid treatment for the first time were classified as group 1; those who had received steroid treatment at another hospital and those who were re-treated were classified as group 2. The treatment results of each group were evaluated.

Results According to the results of this study, the recovery rates for group 1 and 2 were $66.7 \%$ and $31.4 \%$, respectively.

Conclusion Most of the previous studies on the treatment results of sudden hearing loss were performed in tertiary medical institutions. It is likely that the treatment results of patients who recovered after treatment in the primary and secondary medical institutions were missed, which means that the results of steroid therapy may be better than those reported previously.

Korean J Otorhinolaryngol-Head Neck Surg 2019;62(12):681-5

Key Words Recovery of function · Steroid · Sudden sensorineural hearing loss.

\section{서 론}

돌발성 난청은 이과적 응급 질환으로 수 시간 내지 수 일 동 안에 걸쳐 돌발적으로 발생하는 원인 불명의 감각신경성 난 청을 말한다. ${ }^{1)}$ 이비인후과적 응급 질환에 해당되며 빠른 치 료를 요한다. 국내의 경우 대부분의 환자들은 접근성이 좋은

This is an Open Access article distributed under the terms of the Creative Commons Attribution Non-Commercial License (https://creativecommons.org/licenses/by-nc/4.0) which permits unrestricted non-commercial use, distribution, and reproduction in any medium, provided the original work is properly cited.
1 차 의료 기관을 먼저 거치고 호전이 되면 치료를 중단하는 데, 호전이 없거나 난청의 정도가 심한 경우 상급 의료 기관 으로 전원되며, 상급 의료 기관에서는 비교적 고농도의 스테 로이드, 고실 내 스테로이드 주입 등 좀 더 침습적인 치료를 시행하게 된다. ${ }^{23)}$ 기존의 돌발성 난청의 치료 성적에 관한 연 구 논문은 많이 있으나, 대부분 연구에서 연구 대상이 타 병 원에서 스테로이드 치료 후 전원되었는지, 바로 해당 기관에 서 스테로이드 치료를 시작하였는지에 대해서는 명확히 밝히 고 있지 않다. 이에 본 연구에서는 돌발성 난청으로 진단받고 
타 병원에서 스테로이드 치료 후 전원된 환자군과 본원에서 처음 스테로이드 치료를 시작한 환자군의 치료 성적을 비교 해 보고자 한다.

\section{대상 및 방법}

2015년 1월부터 2017년 8월까지 본원 이비인후과에서 돌 발성 난청으로 진단받고 입원 치료를 받은 176 명의 환자들의 의무기록을 후향적으로 분석하였다(IRB No. 2019-11-024). 돌발성 난청의 선정 기준은 뚜렷한 원인 없이 순음 청력검사 상 3 일 이내에 3 개의 연속되는 주파수에서 $30 \mathrm{~dB}$ 이상의 감 각신경성 난청 소견을 보이는 환자로 하였다. ${ }^{1)}$

본원에 바로 방문하였거나 타 의료 기관에서 스테로이드 치료를 시행하지 않고 전원된 환자와 스테로이드 치료를 시 행 후 전원된 환자군으로 나누었으며, 증상 발생 후 본원에 서 치료하기까지 7일 이상이 지난 환자, 전음성 난청이 $10 \mathrm{~dB}$ 이상인 환자, 외상이나 뇌병변에 의한 난청 환자, 변동성의 난청 환자, 스테로이드 치료가 어려운 당뇨, 심혈관 질환이 있는 환자, 타 병원에서 전원되었지만 스테로이드 치료 유무 가 확실하지 않는 경우, 고실 내 스테로이드 주입을 받은 경 우, 분석 대상에서 제외하였으며 최종적으로 127 명의 환자 를 대상으로 연구를 진행하였다. 본원에서 스테로이드 치료 를 처음 받은 환자들을 1 군(group 1), 타 병원에서 스테로이 드 치료를 받고 본원에서 재치료를 받은 환자들을 2군 (group 2)으로 분류하였다.

176 명의 연구 대상 환자 중 연구에 최종 포함된 127 명의 환자를 스테로이드 치료 없이 본원에 처음 방문한 1군 57명, 타 병원에서 스테로이드 치료 후 의뢰된 군 70명으로 나누 었다(Fig. 1). 타 병원에서 치료받은 내용이 불확실한 경우 해당 기관에 연락하여 스테로이드 치료 시행 여부를 확인한 후 분류하였다.

모든 환자에게 prednisolone(Solondo ${ }^{\circledR}$; Yuhan Medica, Seoul, Korea)을 총 10일간 투여하였다. 1 5일까지 $60 \mathrm{mg}$ 을, 남은 5 일간은 절반으로 감량하였다. 모든 환자는 7일 혹은 10 일간 입원하여 절대 안정하였으며 동일한 혈관 확장제(Carnitil $500 \mathrm{mg}$ 1T TID, 아세틸-L-카르니틴염산염 $500 \mathrm{mg}$; Hanmi Pharm., Seoul, Korea)를 사용하였다. 입원 기간동안 항바이러스제 famciclovir $250 \mathrm{mg}$ (Famvir ${ }^{\circledR}$; Novartis, Basel, Switzerland)을 투여하였으며 고실 내 스테로이드 주입술 을 시행하였다.

고실 내 스테로이드 주입은 입원 기간 중 격일로 3 5회 시 행하였으며 앙와위에서 고개를 시술 반대 측으로 돌린 상태 에서 methylprednisolone을 0.4 cc가량 주입하고, 이관을 통

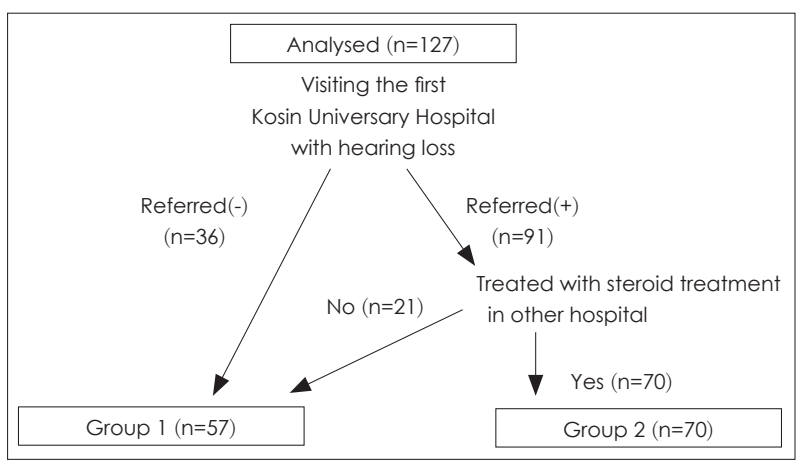

Fig. 1. Classifications of enrolled patients. Total 127 patients were enrolled. Among them, patients who visit Kosin Universary Hospital were 36, 91 patients were referred from other hospital. Among them, patients who were not treated steroid therapy in other hospital were 21 . Therefore, the number of group 1 was 57 . The number of group 2 was 70.

Table 1. The Siegel's criteria of hearing recovery

\begin{tabular}{ll}
\hline \multicolumn{1}{c}{ Type } & \\
$\begin{array}{l}\text { Complete recovery } \\
\text { Partial recovery }\end{array}$ & $\begin{array}{l}\text { Final hearing level was better than } 25 \mathrm{~dB} \\
\text { More than } 15 \mathrm{~dB} \text { of gain, } \\
\text { final hearing } 25-45 \mathrm{~dB}\end{array}$ \\
$\begin{array}{c}\text { Slight improvement } \\
\text { More than } 15 \mathrm{~dB} \text { of gain, } \\
\text { final hearing poorer than } 45 \mathrm{~dB}\end{array}$ \\
$\begin{array}{r}\text { Less than } 15 \mathrm{~dB} \text { of gain, } \\
\text { final hearing poorer than } 75 \mathrm{~dB}\end{array}$ \\
\hline
\end{tabular}

해 배출되지 않도록 약을 삼키지 않게 한 채로 10 분 정도 유 지시켰다.

순음 청력검사는 입원 당시 1 회, 입원 기간 중 격일로 3 회, 퇴원 후 첫 방문 시에 1 회 시행하였으며, 치료 효과는 입원 당 시와 퇴원 후 측정한 순음 청력검사(4주 뒤)를 통해 비교하였 다. 난청의 정도는 경도(mild, $26 ~ 40 \mathrm{~dB}$ ), 중등도(moderate, 41 55 dB), 중등고도(moderately severe, 56 70 dB), 고도(severe, 71 90 dB), 그리고 농(propund, $91 \mathrm{~dB}$ 이상)으로 분류하 였다. 평균 청력 역치는 $500 \mathrm{~Hz}+(1000 \mathrm{~Hz} \times 2)+(2000 \mathrm{~Hz} \times$ 2) $+4000 \mathrm{~Hz}$ 의 합을 6 으로 나눈, 6 분법으로 계산하였으며 치 료 전 순음 청력 역치값에서 치료 후 순음 청력 역치값을 뺀 청력 역치 호전도와 Siegel's criteria(Table 1)를 이용하여 치 료 호전 여부를 판정하였고 ${ }^{4}$ 완전 회복군(complete recovery), 부분 회복군(partial recovery), 경도 회복군(slight improvement)을 청력회복으로 분류하였을 때 두 군 간의 차이가 있 는지를 비교하였다. 증상 발생 후 본원 내원까지의 기간도 두 군 간의 차이가 있는지를 비교하였다. 통계적 분석은 SPSS 24.0(IBM Corp., Armonk, NY, USA)를 통해 카이 제곱 분석 및 Fisher's Exact test, t-검정, Mann-Whitney U test를 시행 하여 두 군을 비교하였다. $p$ 값이 0.05 이하인 경우에 의미가 있는 것으로 판정하였다. 각 자료의 평균은 중앙값과 표준편 차로 표기하였다. 


\section{결 과}

1 군과 2군에서 나이, 성별에 대해서는 유의한 차이를 보이지 않았으며 발병 후 본원이든 타 병원이든 구분 없이 첫 치료가 시행된 기간에서 유의한 차이를 보이지 않았다. 2 군에서 본원 치료 시행되기까지 평균 기간은 더 길었으나 통계적으로 유의 한 차이는 없었다. 1 군과 2 군에서 나이, 성별에 대해서는 각각 46.4 \pm 16.7 세, 49.1 \pm 18.0 세이고 남녀 성비는 각각 25:22, 34:36, 발병 후 본원이든 타 병원이든 구분 없이 첫 치료가 시행된 기 간은 각각 $2.6 \pm 1.4$ 일, $3.2 \pm 1.9$ 일로 카이 제곱 검정을 시행하였 으며 2군에서 본원 치료가 시행되기까지 평균 기간은 더 길었 으나 Mann-Whitney U test를 이용한 통계학적 차이는 없었 다. 각 군에서 차지하는 청력 손실의 심각도는 1 군에서 경도 (mild) 19명(33.3\%), 중등도(moderate) 17명(29.8\%), 중등고도 (moderately severe) 12명(21\%), 고도(severe) 7명(12.2\%), 농 (profound) 2명(3.5\%)이고 2군에서는 경도(mild) 26명(37.1\%), 중등도(moderate) 20명(28.5\%), 중등고도(moderately severe) 12명(20\%), 고도(severe) 8명(11.1\%), 농(profound) 4명(5.7\%)의 분포를 보였다. 그 외 동반된 증상으로 현훈, 이명은 카이 제곱 분석을 시행하였으며 통계학적 차이가 없었다. 각 주파수별 순 음 청력 평균 역치는 1 군의 경우 $0.5 \mathrm{kHz}$ 에서 $50.3 \pm 23.1 \mathrm{~dB}$, $1 \mathrm{kHz}$ 에서 $51.5 \pm 25.0 \mathrm{~dB}, 2 \mathrm{kHz}$ 에서 $49.5 \pm 26.1 \mathrm{~dB}, 4 \mathrm{kHz}$ 에 서 $53.4 \pm 31.3 \mathrm{~dB}, 6$ 분법상 평균은 $51.2 \pm 24.2 \mathrm{~dB}$ 의 수치를 보였 고 2군의 경우는 $0.5 \mathrm{kHz}$ 에서 $50.1 \pm 29.8 \mathrm{~dB}, 1 \mathrm{kHz}$ 에서 53.6 $\pm 29.3 \mathrm{~dB}, 2 \mathrm{kHz}$ 에서 $50.3 \pm 28.6 \mathrm{~dB}, 4 \mathrm{kHz}$ 에서 $55.1 \pm 30.4$ $\mathrm{dB}, 6$ 분법상 평균은 $54.6 \pm 27.7 \mathrm{~dB}$ 의 수치를 보였다. 6 분법상
역치 평균은 Mann-Whitney U test, $0.5 \mathrm{kHz}$ 및 $4 \mathrm{kHz}$ 에서 의 역치는 독립 $\mathrm{t}$ 검정을 이용하였고 모두 통계학적 차이는 없 었다(Table 2). 각 주파수 별로 회복률 평가에서는 1군에서 경 도(mild)군의 완전 회복된 경우(complete recovery)는 8명 (42.1\%), 부분 회복된 경우(partial recovery)는 4명(21.0\%), 경 도 호전된 경우(slight improvement)는 1명(5.3\%)이고 총합은 13 명(68.4\%)이며, 2군에서는 경도(mild)군의 완전 회복된 경우 (complete recovery)는 7명(27.0\%), 부분 회복된 경우(partial recovery)는 5명(19.2\%), 경도 호전된 경우(slight improvement) 는 1명(3.8\%)이고 총합은 13명(50.4\%)으로 양 군의 회복 정도에 따른 통계학적 유의한 차이는 없었다 $(p=0.661,0.647,0.651$, 0.653 ; 카이 제곱 검정).

1 군에서 중등도(moderate)군의 완전 회복된 경우(complete recovery)는 6명(35.2\%), 부분 회복된 경우(partial recovery)는 4명(23.5\%), 경도 호전된 경우(slight improvement)는 3명(17.6\%)이고 총합은 13명(76.4\%)이며, 2군에서는 중등도(moderate)군의 완전 회복된 경우(complete recovery)는 2명(10.0\%), 부분 회복된 경우(partial recovery)는 2 명(10.0\%), 경도 호전된 경우(slight improvement)는 0명 $(0.0 \%)$ 이고 총합은 4 명 $(20.0 \%)$ 으로 양 군의 회복 정도에 따 른 통계학적 차이가 있었다 $(p=0.027,0.048,0.021,0.032 ;$ 카 이 제곱 검정). 1 군에서 중등고도(moderately severe)군의 완 전 회복된 경우(complete recovery)는 2명(16.7\%), 부분 회복 된 경우(partial recovery)는 4명(33.3\%), 경도 호전된 경우 (slight improvement)는 1명(8.3\%)이고 총합은 7명(58.3\%)이 며, 2군에서는 중등고도(moderately severe)군의 완전 회복

Table 2. Baseline demographic and clinical characteristics of patients

\begin{tabular}{|c|c|c|c|}
\hline & Group $1(n=57)$ & Group $2(n=70)$ & p-value \\
\hline Mean age (years) & $46.4 \pm 16.7$ & $49.1 \pm 18.0$ & 0.794 \\
\hline Male:female & $25: 22$ & $34: 36$ & 0.309 \\
\hline Duration from onset to treatment (days) & $2.6 \pm 1.4$ & $3.2 \pm 1.9$ & 0.263 \\
\hline Vertigo (\%) & $21(12)$ & $22(16)$ & 0.074 \\
\hline Tinnitus (\%) & $35(20)$ & $47(33)$ & 0.201 \\
\hline \multicolumn{4}{|l|}{ Severity of hearing loss (\%) } \\
\hline Mild & $33.3(19)$ & $37.1(26)$ & 0.785 \\
\hline Moderate & $29.8(17)$ & $28.5(20)$ & 0.914 \\
\hline Moderately severe & $21.0(12)$ & $20.0(12)$ & 0.884 \\
\hline Severe & $12.2(7)$ & $11.1(8)$ & 0.946 \\
\hline Profound & $3.5(2)$ & $5.7(4)$ & 0.431 \\
\hline \multicolumn{4}{|l|}{ Hearing level in each frequency $(\mathrm{dB})$} \\
\hline $0.5 \mathrm{kHz}$ & $50.3 \pm 23.1$ & $50.1 \pm 29.8$ & \\
\hline $1 \mathrm{kHz}$ & $51.5 \pm 25.0$ & $53.6 \pm 29.3$ & \\
\hline $2 \mathrm{kHz}$ & $49.5 \pm 26.1$ & $50.3 \pm 28.6$ & \\
\hline $4 \mathrm{kHz}$ & $53.4 \pm 31.3$ & $55.1 \pm 30.4$ & \\
\hline Pure tone audiometry average & $51.2 \pm 24.2$ & $54.6 \pm 27.7$ & \\
\hline
\end{tabular}


된 경우(complete recovery)는 1명(8.3\%), 부분 회복된 경우 (partial recovery)는 2명(16.7\%), 경도 호전된 경우(slight improvement)는 0 명 $(0.0 \%)$ 이고 총합은 3명(25.0\%)으로 양 군의 회복 정도에 따른 통계학적 차이가 있었다 $(p=0.027$, 0.023, 0.012, 0.021; 카이 제곱 검정).

1 군에서 고도(severe)군의 완전 회복된 경우(complete recovery)는 2명(28.6\%), 부분 회복된 경우(partial recovery)는 1 명(14.3\%), 경도 호전된 경우(slight improvement) 1명 (14.7\%)이고 총합은 7명(58.3\%)이며, 2군에서는 고도(severe) 군의 완전 회복된 경우(complete recovery)는 1명(12.5\%), 부 분 회복된 경우(partial recovery)는 1명(12.5\%), 경도 호전된 경우(slight improvement)는 0명(0.0\%)이고 총합은 2명 (25.0\%)으로 부분 회복된 경우를 제외한 $(p=0.088$, 카이 제곱 검정 $)$ 양 군의 회복 정도에 따른 통계학적 차이가 있었다 $(p=$ $0.041,0.012,0.047$; 카이 제곱 검정). 농(profound)군의 경우 는 부분 회복된 경우(partial recovery)만 있었으며 1군의 경 우 1명(50\%), 2군의 경우 1명(25\%)으로 통계학적 차이가 없었 다 $(p=0.917$, 카이 제곱 검정)(Table 3$)$.

1 군에서 2 군에 비해 전체 회복률 비교 및 증상의 중증도 별 회복률에 있어 경도(mild)군과 농(profound)군은 유의한 차이가 없었으나 그 외 군들은 유의한 차이를 나타냈다. 전 체 군의 회복률은 유의한 차이가 있었다(Table 3).

\section{고 찰}

돌발성 난청은 병인이 다양하므로 스테로이드, 항바이러스 제, 이뇨제, 혈관 확장제 등 항염증 작용 및 혈류 개선을 목적 으로 하는 치료법이 주로 이용되고 있다. Wilson 등하의 연구 에 의하면 전향적 연구를 통해 특히 중고도 이상의 난청에서 스테로이드가 가장 효과적인 치료제이며 치료 시작 시기가 빠 를수록 청력 회복률이 높음을 보고하였다. 하지만 대부분의 논문에서 처음 치료하는 환자군인지 타 의료 기관에서 스테 로이드 치료 후 전원된 환자인지에 대해서는 명확히 밝히지 않고 있다. 본 연구에서는 의료 접근성이 용이한 국내에서의 의료현실상 돌발성 난청이 1 차 의료 기관에서도 많은 치료가 수행되고 있는 점을 고려하여 본원에서 스테로이드를 처음 사 용한 초치료군(group 1)과 타 병원에서 스테로이드 치료를 시 행 후 전원된 환자군인 재치료군(group 2)으로 나누어 각 군 간의 특성 및 회복률을 비교하였다. 성별, 나이, 동반 증상, 치 료 전 순음 청력검사 결과값은 유의한 차이가 없었으며 치료 성적에 영향을 미칠 수 있는 중요한 인자인 병이 발생한 후 치 료받기까지의 기간 또한 차이가 없었다. 회복률 평가에서는 완 전 회복률, 부분 회복률, 경도의 개선을 합친 값을 비교하였고
Table 3. The comparison of recovery rate between two groups

\begin{tabular}{|c|c|c|c|}
\hline \multirow[b]{2}{*}{ Severity of hearing loss } & \multicolumn{3}{|c|}{ Recovery rate } \\
\hline & $\begin{array}{l}\text { Group } 1 \\
(n=57)\end{array}$ & $\begin{array}{l}\text { Group } 2 \\
(n=70)\end{array}$ & $p$-value \\
\hline \multicolumn{4}{|l|}{ Mild (\%) } \\
\hline Complete recovery & $42.1(8 / 19)$ & $27.0(7 / 26)$ & 0.661 \\
\hline Partial recovery & $21.0(4 / 19)$ & $19.2(5 / 26)$ & 0.647 \\
\hline Slight improvement & $5.3(1 / 19)$ & $3.8(1 / 26)$ & 0.651 \\
\hline Subtotal & $68.4(13 / 19)$ & $50.0(13 / 26)$ & 0.653 \\
\hline \multicolumn{4}{|l|}{ Moderate (\%) } \\
\hline Complete recovery & $35.2(6 / 17)$ & $10.0(2 / 20)$ & 0.027 \\
\hline Partial recovery & $23.5(4 / 17)$ & $10.0(2 / 20)$ & 0.048 \\
\hline Slight improvement & $17.6(3 / 17)$ & $0.0(0 / 20)$ & 0.021 \\
\hline Subtotal & $76.4(13 / 17)$ & $20.0(4 / 20)$ & 0.032 \\
\hline \multicolumn{4}{|l|}{ Moderately severe (\%) } \\
\hline Complete recovery & $16.7(2 / 12)$ & $8.3(1 / 12)$ & 0.027 \\
\hline Partial recovery & $33.3(4 / 12)$ & $16.7(2 / 12)$ & 0.023 \\
\hline Slight improvement & $8.3(1 / 12)$ & $0.0(0 / 12)$ & 0.012 \\
\hline Subtotal & $58.3(7 / 12)$ & $25.0(3 / 12)$ & 0.021 \\
\hline \multicolumn{4}{|l|}{ Severe (\%) } \\
\hline Complete recovery & $28.6(2 / 7)$ & $12.5(1 / 8)$ & 0.041 \\
\hline Partial recovery & $14.3(1 / 7)$ & $12.5(1 / 8)$ & 0.088 \\
\hline Slight improvement & $14.3(1 / 7)$ & $0.0(0 / 8)$ & 0.012 \\
\hline Subtotal & $57.1(4 / 7)$ & $25.0(2 / 8)$ & 0.047 \\
\hline \multicolumn{4}{|l|}{ Profound (\%) } \\
\hline Partial recovery & $50.0(1 / 2)$ & $25.0(1 / 4)$ & 0.917 \\
\hline Total & $66.7(38 / 57)$ & $31.4(22 / 70)$ & 0.041 \\
\hline
\end{tabular}

1 군에서 $66.7 \%, 2$ 군에서 $31.4 \%$ 로 유의한 차이를 보였다. 본 연 구에서는 1 군에서 2 군에 비해 증상의 중증도별 회복률에 있 어 경도(mild)군과 농(profound)군은 통계적으로 유의한 차이 가 없었는데, 이는 경도(mild)군의 경우 1군 및 2군 모두 예후 가 좋기 때문이라고 추정되며 농(profound)군은 양 군 모두 치료에 반응이 없어 유의한 차이가 없던 것으로 추정된다. 다 만 $\mathrm{n}$ 수가 너무 적으므로 통계 분석을 하기에 한계가 있었다.

돌발성 난청의 회복률은 일반적으로 $1 / 3$ 은 정상 청력을 되 찾지만 $1 / 3$ 은 청력이 $40 \sim 60 \mathrm{~dB}$ 정도 손상되며 $1 / 3$ 은 청력을 잃는다고 보고되었다. ${ }^{6}$ 또, 전신적 스테로이드와 고실 내 스 테로이드 주입술 병행과 같은 치료 방법에 따른 회복률 평가 를 시행한 연구에서는 단독 시행한 경우 회복률이 $52.3 \%$, 병 행한 경우 $61.9 \%$ 로 다양하게 보고되고 있으며) 예후인자에

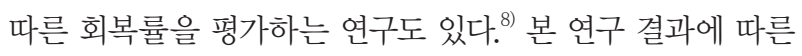
초치료군과 재치료군의 회복율은 $66.7 \%, 31.4 \%$ 로 상당한 차 이를 나타내었다. 이는 재치료군의 경우 위에서 언급한 대로 청력 회복이 적거나 없어 상급 의료 기관으로 전원되는 경우 가 대부분이고 본 기관에서의 치료에도 잘 반응하지 않는 경 우가 많았던 것으로 생각된다. 접근성이 우수한 한국의 의료 
현실에서 돌발성 난청이 발생한 경우 상당수의 환자들은 1 차 의료 기관을 우선적으로 찾게 되며 해당 기관에서 치료 후 회복되나, 이것은 통계적으로 회복률 평가에 반영이 되지 않 는다. 따라서 본 연구의 결과는 단순히 상급 의료 기관에서 의 치료 성적이 높음을 말하는 것이 아니라 돌발성 난청의 치료 방법에 따른 성적에 대해서 평가를 기존 연구가 대부분 3 차 의료 기관에서 이루어졌고 1 차 및 2 차 의료 기관에서 치 료 후 회복된 환자들의 치료 성적이 누락되었을 가능성이 높 아 실제 돌발성 난청의 스테로이드 치료의 성적이 기존 발표 된 결과보다 더 좋을 수 있음을 의미한다.

본 연구의 한계점으로 첫째, 선별 과정에서 조건을 충족시 키지 못하는 경우가 많아 많은 환자군들이 제외되었기에 환 자군의 수가 적다는 점이다. 또한 돌발성 난청의 예후에 중요 한 것으로 알려진, 어지럼증 동반, 청력 소실의 심각도, 나이 등이 제대로 반영되지 않아 회복 결과 평가에 있어 선택의 치우침이 있을 수 있다고 생각된다.,10)

따라서 한계점을 보완하여 향후 돌발성 난청 환자의 연구 에 있어 전원되지 않고 치료된 1차 의료 기관의 환자군을 포 함한 대규모 다 기관 연구가 진행된다면 좀 더 의미 있는 결과 가 도출될 것으로 생각된다.

\section{Acknowledgments}

None.

\section{ORCID}

Jae Beom Ko

\section{REFERENCES}

1) Whitaker S. Idiopathic sudden hearing loss. Am J Otol 1980;1(3): 180-3.

2) Battaglia A, Burchette R, Cueva R. Combination therapy (intratympanic dexamethasone + high-dose prednisone taper) for the treatment of idiopathic sudden sensorineural hearing loss. Otol Neurotol 2008;29(4):453-60.

3) Shin SO. Clinical characteristics and management of sudden sensorineural hearing loss. Korean J Audiol 2011;15(1):1-7.

4) Kim YJ, Jang SU, Lee HH, Kwon JH. Comparison of the effect of intratympanic steroid injection medications in patients with idiopathic sudden sensorineural hearing loss. Korean J Otorhinolaryngol-Head Neck Surg 2017;60(2):441-8.

5) Wilson WR, Byl FM, Laird N. The efficacy of steroids in the treatment of idiopathic sudden hearing loss. A double-blind clinical study. Arch Otolaryngol 1980;106(12):772-6.

6) Yoon TH, Paparella MM, Schachern PA, Alleva M. Histopathology of sudden hearing loss. Laryngoscope 1990;100(7):707-15.

7) Cho CH, Han GC, Cha HE, Woo JH. Analysis of prognostic factors in patients with sudden sensorineural hearing loss. J Clinical Otolaryngol 2005;16(4):89-95.

8) Beak MK, Cho CH, Bang YJ, Oh NR, Baek MJ, Lee JH. Hearing outcomes and prognostic factors in idiopathic sudden sensorineural hearing loss patients with combined intratympanic and systemic steroid therapy. Korean J Otorhinolaryngol-Head Neck Surg 2018;61(5):242-6.

9) Yim KC, Park KY, Lee KI, Kim JY, Chun KD. Clinical analysis of sudden hearing loss. Korean J Otorhinolaryngol-Head Neck Surg 1995;38(6):834-41.

10) Byl FM Jr. Sudden hearing loss: Eight years' experience and suggested prognostic table. Laryngoscope 1984;94(5 Pt 1):647-61. 